\title{
Airflow Stability and Diagonal Mine Ventilation System Optimization: A Case Study
}

\author{
M. Bascompta*, L. Sanmiquel**, and H. Zhang*** \\ Polytechnic University of Catalonia, Manresa 08242, Barcelona, Spain \\ *e-mail: marc.bascompta@upc.edu \\ **e-mail:lluis.sanmiquel@upc.edu \\ ***e-mail:h.zhang@upc.edu
}

\begin{abstract}
Airflow reverse is a severe problem in an underground ventilation system. In addition, the airflow stability and safety production can be seriously affected by the problem of air velocity overrun in the roadways. In this study the crucial causes of the ventilation problems in a coal mine case study are analyzed and a solution is proposed through an analytical methodology. Measurements indicate high air resistance in the shaft and low values in the maintenance roadway, generating abnormal airflow directional behaviors. Strategies to solve the ventilation-related problems have been proposed and implemented, verifying normal ventilation conditions.
\end{abstract}

Keywords: Airflow reverse, velocity overrun, ventilation system, coal mining.

\section{INTRODUCTION}

The development of coal mining mechanization and the increase of production can create air disorder problems in shafts and roadways [1]. Ventilation systems are critical components of the mining system to effectively remove hazardous gas and keep and acceptable temperature [2]. The effect of mine ventilation depends on airflow quantity and its distribution in the ventilation networks, which changes during the mine life [3]. Therefore, the necessity to maintain the airflow required in all workplaces is important to guarantee mine safety production $[4,5]$. However, many different ventilation layouts can be found out $[6,7]$, thus, the strategy to solve the ventilation-related problems in an underground mine should be according to the real situation in each case study [8, 9]. According to [10], the behaviour of the ventilation system is dynamic and air demand increases as the mine is developed, requiring sometimes the installation of additional ventilation shafts, upgrading fans or enlarging existing airways [11]. A system simply designed to comply with the legal minimum airflows or air velocity may be inadequate for the purpose of maintaining a safe and satisfactory environment in an active mine. For this reason, the expected worst-case pollutant levels have to be taken into account in the design stage [12]. Moreover, three key factors should be considered during the design and optimization: breathable air effectively delivered to working zones, temperatures control and dangerous gases and airborne dust removed or diluted [13-15]. These factors are important in all types of underground mining, but it becomes crucial in coal mining because of its intrinsic characteristics [16], where airflow has to be optimized to ensure dilution of gas, dust and heat [17-19]. However, this dilution process is inherently limited by air availability within the mine and maximum tolerable air velocities [20]. 


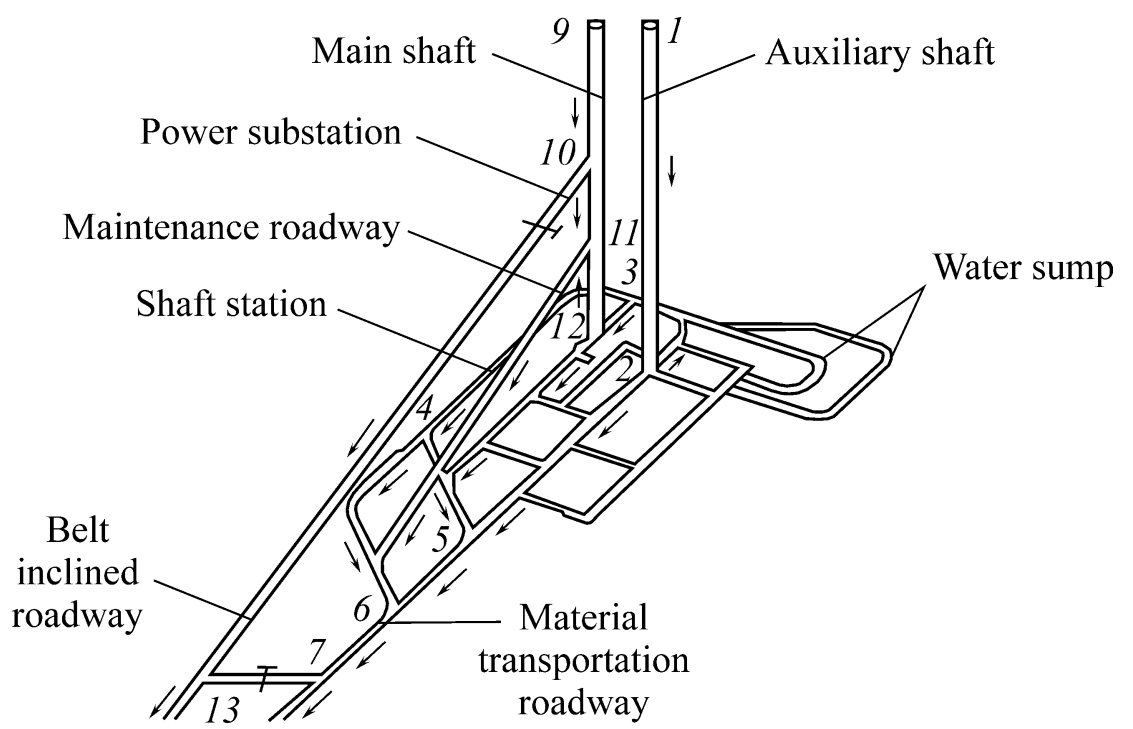

Fig. 1. Airflow route in the ventilation system before adjustment.

This paper is based on a case study coal mine and it is focused on the cause of air disorder problems in roadways, drifts and shafts with multilevel and complicated diagonal ventilation systems. The work provides multiple effective solutions.

\section{THEORY AND METHODS}

Two vertical shafts are used as intake, with a total depth over $500 \mathrm{~m}$. The main vertical shaft is used for lifting and inlet air, while the auxiliary vertical shaft is used for auxiliary lifting, inlet air and emergency exit.

The ventilation system of the mine is designed as a two-way diagonal ventilation system. However, the air disorder problem in the shaft station and roadways has been become increasingly severe with the increase of coal mining output. The production schedule is seriously affected by the airflow reverse in the main vertical shaft and the airflow velocity overrun in the material roadway. Figure 1 shows the ventilation route of the coal mine before the adjustment. The different numbers correspond to the nodes used to draw the ventilation circuit.

Diagonal ventilation system is a complex system with many diagonal branches inside, but it is regarded as simple diagonal ventilation system when it only has one diagonal branch. Figure 2 shows a simplified example, where branch 5 is the diagonal and it is enclosed by nodes 2 and 3 . Its distinctive feature is the airflow can reverse depending on the resistance of the drifts.

A relationship of the airflow resistance has been proposed to analyse the criterion of the airflow direction in the diagonal branch exposed in Fig. 2:

$$
K=\frac{R_{1} R_{4}}{R_{2} R_{3}},
$$

when $K>1$, the air flows from node 3 to 2 in branch 5 ; when $K=1$, there is no airflow in branch 5 ; when $K<1$, the airflows from node 2 to 3 in branch 5 .

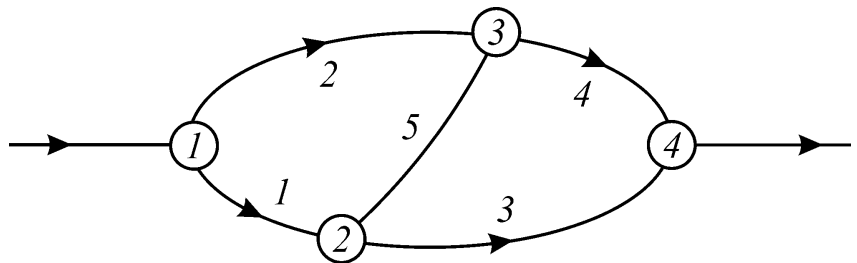

Fig. 2. Simple diagonal ventilation system. 
While the total ventilation resistance of the simple diagonal for nodes $1-2-4$ can be obtained, when $Q_{1}>0$ and $Q_{3}>0$ by the equation:

$$
R=\frac{R_{1} Q_{1}^{2}+R_{3} Q_{3}^{2}}{Q^{2}},
$$

where $K$ is the discriminant coefficient of the airflow direction of the diagonal; $R$ is the total ventilation resistance of the diagonal, $\mathrm{N} \cdot \mathrm{s}^{2} / \mathrm{m}^{8} ; Q$ is the total air quantity of the diagonal, $\mathrm{m}^{3} / \mathrm{s} ; R_{i}$ is the air resistance of each branch $(i=1,2,3,4 \ldots), \mathrm{N} \cdot \mathrm{s}^{2} / \mathrm{m}^{8} ; Q_{i}$ is the airflow of each branch $(i=1,2,3,4 \ldots), \mathrm{m}^{3} / \mathrm{s}$.

Equation (2) can be used to obtain the resistance between the start and the end of a diagonal drift, and an analogous variation of the expression could also be used for another other path within the interval of nodes 1 to 4 .

Complex diagonal systems contain two or more diagonal branches. Based on the principle of node mergence and actual requirement, some short distance and low resistance nodes are merged. The way of simplifying the diagonal ventilation system involved three steps. The first one is carefully analysing airflow direction of the diagonal ventilation system and branches, the second step is finding the branches with unreasonable airflow direction according to the actual requirements and the last step is adjusting and optimizing the system [21].

The complex diagonal ventilation system has different levels and it consists of main vertical shaft, auxiliary vertical shaft, belt roadway, coal bunker, material transportation roadway, shaft station, air inlet, air outlet and secondary roadways. Airflow direction in the diagonal ventilation system can be affected when the air resistance of a branch is changed. Thus, the underground ventilation system of the mine should be constantly reformed and optimized. In this direction, some changes have been applied to simplify the ventilation system. It can be seen from Fig. 1 that node 2 is close to node 12; node 7 is close to node 13 , having low resistances due to their small length. Therefore, node 2 was merged with node 12 , named node 12 ; node 7 was merged with node 13 , named node 7 (Fig. 3 ).

It can be referred from Fig. 3 that two underground simple diagonal ventilation systems can be changed into one complex diagonal ventilation system if node 10 merges with node 11 and node 6 merges with node 7 , having the new node numbers are 11 and 7 respectively, as it can be seen in Fig. 4. Subsequently, the underground ventilation system can be separated into two simple diagonal ventilation systems. The first diagonal consists of material transportation roadway, clean roadway and shaft station, the other diagonal consists of main vertical shaft, auxiliary vertical shaft and belt roadway.

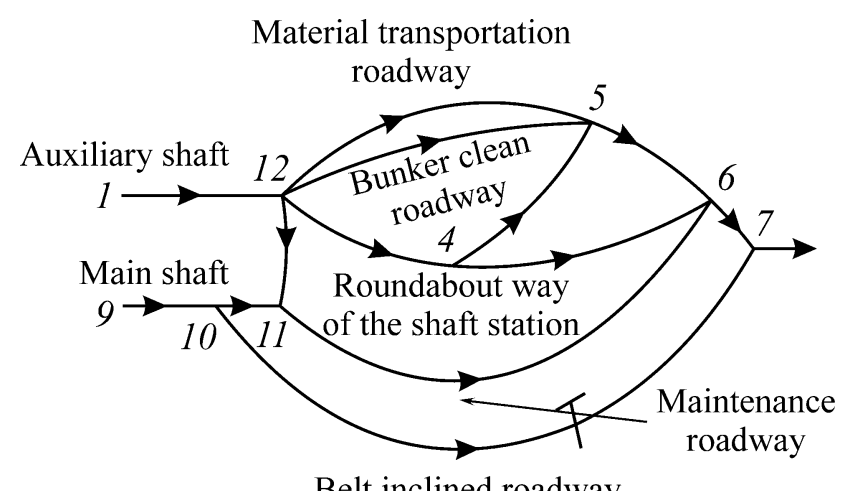

Belt inclined roadway

Fig. 3. First simplification of the ventilation network. 


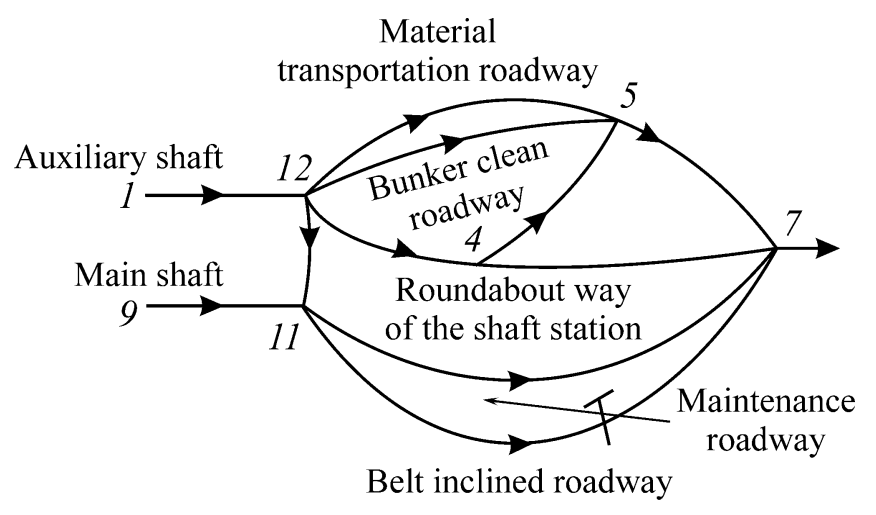

Fig. 4. Optimized underground roadways and ventilation system.

Multiple measurements of airflow and pressure drop have been done along the ventilation circuit. The total airflow is $170.8 \mathrm{~m}^{3} / \mathrm{s}$, which is divided between the main and auxiliary shaft $-43 \mathrm{~m}^{3} / \mathrm{s}$ and $127.7 \mathrm{~m}^{3} / \mathrm{s}$, respectively. The airflow reversed from the bottom to the top in the main shaft (nodes $11 \rightarrow 12)$ is $12.7 \mathrm{~m}^{3} / \mathrm{s}$. Table 1 displays the main parameters measured in the ventilation system.

According to equations (1) and (2), Fig. 4 and Table 1, the total air resistance of local diagonal ventilation system (node $12 \rightarrow$ node 7 and node $11 \rightarrow$ node 7 ) is calculated as follows:

$$
R_{d}=\frac{R_{12-4} Q_{12-4}^{2}+R_{4-7} Q_{4-7}^{2}}{Q_{d}^{2}}=0.662 \cdot 10^{-2},
$$

where $Q_{d}$ is the airflow in a diagonal connection system, $\mathrm{m}^{3} / \mathrm{s}$;

$$
R_{11-7}=\frac{1}{\left(\sqrt{\frac{1}{R_{m}}}+\sqrt{\frac{1}{R_{b}}}\right)^{2}}=1.128 \cdot 10^{-2}
$$

$R_{m}$ is the maintenance roadway air resistance; $R_{b}$ is the belt roadway air resistance.

Discriminant coefficient:

$$
K=\frac{R_{m} R_{d}}{R_{a} R_{11-7}}=5.7>1,
$$

here, $R_{m}$ is the main vertical shaft air resistance; $R_{a}$ is the auxiliary vertical shaft air resistance.

Table 1. Airflow parameters in the ventilation system

\begin{tabular}{c|l|c|c}
\hline Nodes & \multicolumn{1}{|c|}{ Roadway } & Airflow, $\mathrm{m}^{3} / \mathrm{s}$ & Pressure drop, Pa \\
\hline $1 \rightarrow 2$ & Auxiliary vertical shaft & 127.7 & 345.6 \\
$2 \rightarrow 5$ & Material transportation roadway & 74.1 & 44.2 \\
$5 \rightarrow 6$ & Material transportation roadway & 101.7 & 42.1 \\
$6 \rightarrow 7$ & Material transportation roadway & 157.7 & 143.6 \\
$9 \rightarrow 10$ & Main vertical shaft & 43.1 & 394.8 \\
$10 \rightarrow 11$ & Main vertical shaft & 30.0 & 11.7 \\
$12 \rightarrow 11$ & Main vertical shaft & 12.7 & 3.7 \\
$2 \rightarrow 4$ & Roundabout way of shaft station & 42.3 & 42.6 \\
$10 \rightarrow 13$ & Inclined belt roadway & 13.0 & 180.9 \\
$11 \rightarrow 6$ & Maintenance roadway & 42.7 & 25.5 \\
\hline
\end{tabular}


Due to the discriminant coefficient $K>1$, the airflow direction is changed to opposite direction, node $12 \rightarrow$ node 11 . The reason of airflow reverse is that the air resistance of local diagonal ventilation system (main vertical shaft, node 12 and node 7) is very high, while the air resistance of parallel roadway (auxiliary vertical shaft, node 11 and node 7 ) is lower.

The air resistance of the main vertical shaft is impossible to reduce because of the activity of lifting. On the other hand, the airflow would be decreased if the air resistance in the auxiliary vertical shaft is increased, which would generate a negative influence on the activity. Resistance of the local diagonal ventilation system can be extracted from Fig. 4, where node $12 \rightarrow$ node 5 is $0.575 \cdot 10^{-2} \mathrm{~N} \cdot \mathrm{s}^{2} / \mathrm{m}^{8}$; node $5 \rightarrow$ node 7 is $0.407 \cdot 10^{-2} \mathrm{~N} \cdot \mathrm{s}^{2} / \mathrm{m}^{8}$; node $2 \rightarrow$ node 4 is $2.388 \cdot 10^{-2} \mathrm{~N} \cdot \mathrm{s}^{2} / \mathrm{m}^{8}$ and node $4 \rightarrow$ node 7 is $25.33 \cdot 10^{-2} \mathrm{~N} \cdot \mathrm{s}^{2} / \mathrm{m}^{8}$. Besides, the resistance of the parallel roadway (node $11 \rightarrow$ node 7 ) is lower than the inclined belt roadway of upper coal bunker $106.73 \cdot 10^{-2} \mathrm{~N} \cdot \mathrm{s}^{2} / \mathrm{m}^{8}$.

Table 1 also shows that the total pressure drop in the ventilation roadway $(1 \rightarrow 2 \rightarrow 5 \rightarrow 6 \rightarrow 7)$ is $575.4 \mathrm{~Pa}$ and it is made up of two high-resistance branches. The first is the auxiliary shaft (node 1 $\rightarrow$ node 2) with a pressure drop of $345.6 \mathrm{~Pa}$ due to a double-layer cage and ladder roadway for lifting and safety entrance, while the second branch is the material transportation roadway (node $6 \rightarrow$ node 7 ) with a drop of $143.6 \mathrm{~Pa}$.

Regarding the branch with node $6 \rightarrow$ node 7 , it has a length of $85 \mathrm{~m}$ only, but the air resistance is very high $(143.6 \mathrm{~Pa})$ because of its airflow $\left(157.73 \mathrm{~m}^{3} / \mathrm{s}\right)$ which is almost equal to the total airflow of the whole mine, reaching a velocity of $11.56 \mathrm{~m} / \mathrm{s}$. This high velocity is above the limit of many national regulations and it can cause problems, especially if it is a drift with regular activities [22].

Thus, the analysis of the data suggests that there are two reasons resulted in the airflow reverse in the main shaft bottom (node $11 \rightarrow$ node 12 ). Firstly, the air resistance (node $4 \rightarrow$ node 7 ) is quite higher than in the maintenance roadway; secondly, the airflow is over-accumulated in the roadway node $6 \rightarrow$ node 7 .

\section{OPTIMIZATION PROPOSAL}

Based on the actual situation, multiple countermeasures are proposed to combat the problem of airflow reverse in accordance with the staff of the mine. Air regulators are installed in order to increase the air resistance in the maintenance roadway. The air resistance of parallel roadway (node $11 \rightarrow$ node 7 ) will be increased, if the air resistance of the maintenance roadway is increased. Besides, for the purpose of solving the high air resistance problem (node $4 \rightarrow$ node 7 ) and reduce the air velocity overrun (node $6 \rightarrow$ node 7 ), an air inlet with the length of $165 \mathrm{~m}$ was excavated between the shaft station and east track roadway. The shaft station (node $3 \rightarrow$ node 4 ) is extended to the east track roadway and joint to node 14 . Therefore, the air resistance (node $4 \rightarrow$ node 7 ) is dramatically decreased, which also reduces the air resistance of the local diagonal ventilation system (node $12 \rightarrow$ node 7 ). Moreover, the problem of air velocity overrun in roadway (node $6 \rightarrow$ node 7 ) is completely solved because the new excavated roadway can be used as a material transportation roadway and it can reduce the airflow through the roadway (node $6 \rightarrow$ node 7 ). The optimized ventilation system proposed can be seen in Fig. 5.

According to the principle of merging the adjacent nodes, nodes 2,3 and 12 are merged and named as 12 , nodes 10 and 11 are merged and named as 11 , and nodes $6,7,8,13$ and 14 are merged and named as 7 . The optimized roadways and ventilation system can be seen in Fig. 6, while the key parameters of the underground roadways are shown in Table 2. 


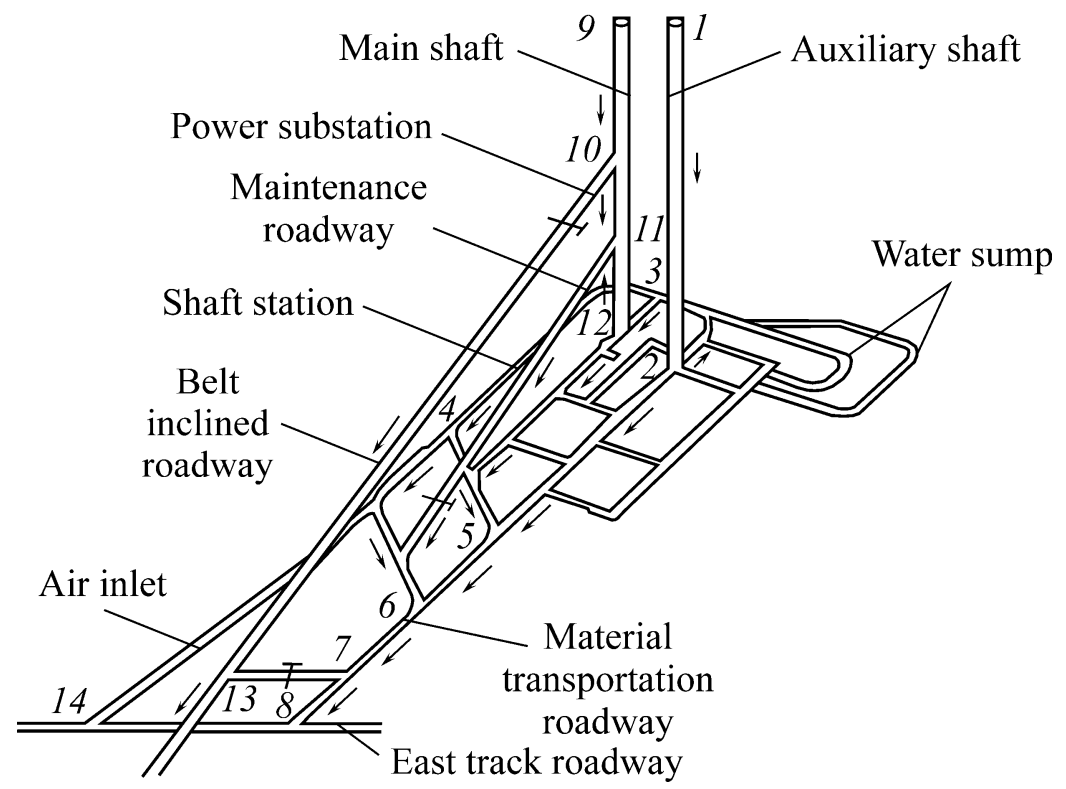

Fig. 5. Optimized ventilation system.

According to Fig. 6, Tab. 2, and the air resistance calculation of parallel connection roadway, the air resistances of the optimized parallel connection roadway (node $4 \rightarrow$ node 7 ) are calculated:

$$
R_{4-7}=\frac{1}{\left(\sqrt{\frac{1}{R_{r}}}+\sqrt{\frac{1}{R_{i}}}\right)^{2}}=0.687 \cdot 10^{-2}
$$

where $R_{r}, R_{i}$ is the aerodynamic air resistance of the shaft station and air inlet roadway, $\mathrm{N} \cdot \mathrm{s}^{2} / \mathrm{m}^{8}$.

Air resistances of optimized parallel connection roadway (node $11 \rightarrow$ node 7 ) are calculated as follows:

$$
R_{11-7}^{\prime}=\frac{1}{\left(\sqrt{\frac{1}{R_{m}^{\prime}}}+\sqrt{\frac{1}{R_{b}}}\right)^{2}}=12.71 \cdot 10^{-2} .
$$

According to (1), (2), Fig. 6, Tab. 2, the air resistance of the diagonal (node $12 \rightarrow$ node 7 ) and the direction discriminant coefficient $K$ are calculated:

$$
R_{d}^{\prime}=\frac{R_{12-4} Q_{12-4}^{2}+R_{4-7}^{\prime} Q_{4-7}^{2}}{Q_{d}^{2}}=0.435 \cdot 10^{-2}, \quad K=\frac{R_{m} R_{d}^{\prime}}{R_{a} R_{11-7}^{\prime}}=0.33<1 .
$$

Material

transportation roadway

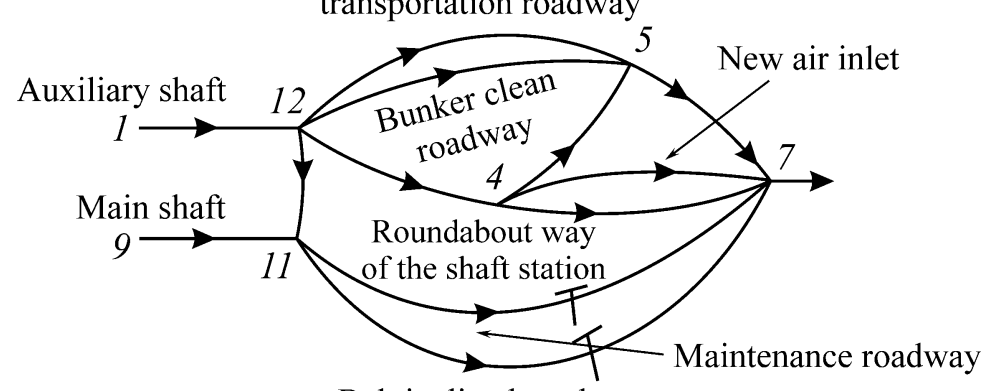

Belt inclined roadway

Fig. 6. Optimized roadways and ventilation system. 
Table 2. Optimized ventilation system measures

\begin{tabular}{c|l|c|c}
\hline Node number & \multicolumn{1}{|c|}{ Roadway } & Airflow, $\mathrm{m}^{3} / \mathrm{s}$ & Pressure drop, Pa \\
\hline $1 \rightarrow 2$ & Auxiliary vertical shaft & 130.2 & 359.3 \\
$2 \rightarrow 5$ & Material transportation roadway & 88.3 & 62.7 \\
$5 \rightarrow 6$ & Material transportation roadway & 65.2 & 17.3 \\
$6 \rightarrow 7$ & Material transportation roadway & 83.0 & 39.8 \\
$9 \rightarrow 10$ & Main vertical shaft & 42.1 & 376.8 \\
$10 \rightarrow 11$ & Main vertical shaft & 32.4 & 13.7 \\
$12 \rightarrow 11$ & Main vertical shaft & 19.6 & 8.9 \\
$2 \rightarrow 4$ & Roundabout way of shaft station & 46.9 & 52.6 \\
$4 \rightarrow 14$ & Air inlet roadway & 79.6 & 62.3 \\
$10 \rightarrow 13$ & Belt roadway of upper coal bunker & 9.7 & 99.4 \\
$11 \rightarrow 6$ & Maintenance roadway & 12.8 & 48.5 \\
\hline
\end{tabular}

The discriminant coefficient $K$ gives the value lower than 1, therefore, the airflow direction of the main vertical shaft is completely changed from node $12 \rightarrow$ node 11 to node $11 \rightarrow$ node 12 after the ventilation system is optimized, solving the problem of airflow reverse in the ventilation system.

Besides, the airflow in the auxiliary vertical shaft is divided into two airflow branches to flow into the eastern roadway, the first one is node $2 \rightarrow 5 \rightarrow 6 \rightarrow 7$ and the second one is node $2 \rightarrow 3 \rightarrow 4 \rightarrow 14$. Thus, the accumulated air in the roadway (node $2 \rightarrow$ node 7 ) is reduced, the air resistance is lowered and the problem of air velocity overrun in the roadway (node $2 \rightarrow$ node 7 ) is effectively solved, the air velocity decreased from 11.6 to $6.1 \mathrm{~m} / \mathrm{s}$ after the ventilation system is optimized. The parameters of the optimized ventilation system are given below.

$\begin{array}{lc}\text { Total inlet airflow, } \mathrm{m}^{3} / \mathrm{s} & 170.8 / 172.3 \\ \text { Air drop, } \mathrm{Pa} & 609.3 / 490.7 \\ \text { Airflow direction, nodes } 11-12 & 12 \rightarrow 11 / 11 \rightarrow 12 \\ \text { Air velocity of transportation roadway, } \mathrm{m} / \mathrm{s} & 11.6 / 6.1\end{array}$

\section{CONCLUSIONS}

The diagonal ventilation system should be constantly optimized for the purpose of improving the airflow stability and the safety production. The study offers an overall analysis about the reason of air disorder problems in drifts, tunnels and shafts with multilevel and complicated diagonal ventilation systems, as well as providing a series of solutions in a case study. Through merging the nodes and optimizing the ventilation system, the underground problems of the airflow reverse in the vertical shaft and the airflow velocity overrun are completely solved, changing the resistance of several parts of the ventilation circuit and still providing enough airflow to the underground workings.

\section{ACKNOWLEDGMENTS}

The authors would like to thank the ICL Chair in Sustainable Mining for important contributions to this research and providing data.

\section{REFERENCES}

1. Wallace, K., Prosser, B., and Stinnette, J.D., The Practice of Mine Ventilation Engineering, Int. J. Min. Sci. Tech., 2015, vol. 25, no. 2, pp. 165-169.

2. Wang, L., Cheng, Y.P., Ge, C.G., Chen, J.X., Li, W., Zhou, H.X., and Hai-feng, W., Safety Technologies for the Excavation of Coal and Gas Outburst-Prone Coal Seams in Deep Shafts, Int. J. Rock Mech. Min. Sci., 2013, vol. 57, pp. 24-33.

3. Song, Y.H., Guo, X.Y., Lv. W., Guo, H., and Li, R.Y., A Simulation Study on the Reconstruction of Coalmine Ventilation System Based on Wind Resistance Correction, Int. J. Simulation Modelling, 2017, vol. 16, no. 1, pp. 31-44. 
4. Kruglov, Y.V., Levin, L.Y., and Zaitsev, A.V., Calculation Method for the Unsteady Air Supply in Mine Ventilation Networks, J. Min. Sci., 2011, vol. 47, no. 5, pp. 651-659.

5. Chen, K., Si, J., Zhou, F., Zhang, R., Shao, H., and Zhao, H., Optimization of Air Quantity Regulation in Mine Ventilation Networks Using the Improved Differential Evolution Algorithm and Critical Path Method, Int. J. Min. Sci. Tech., 2015, vol. 25, no. 1, pp. 79-84.

6. Chatterjee, A., Zhang, L., and Xia, X., Optimization of Mine Ventilation Fan Speeds According to Ventilation on Demand and Time of Use Tariff, Applied Energy, 2015, vol. 164, pp. 65-73.

7. Kozyrev, S.A. and Osintseva, A.V., Optimizing Arrangement of Air Distribution Controllers in Mine Ventilation System, J. Min. Sci., 2012, vol. 48, no. 5, pp. 896-903.

8. Greuer, R.E., Modeling the Movement of Smoke and the Effect of Ventilation Systems in Mine Shaft Fires, Fire Safety J., 1985, vol. 9, no. 1, pp. 81-87.

9. Khan, M.M. and Krige, G.J., Evaluation of the Structural Integrity of Aging Mine Shafts, Engineering Structure, 2002, vol. 24, no. 7, pp. 901-907.

10. Toraño, J., Torno, S., Menendez, M., Gent, M., and Velasco, J., Models of Methane Behaviour in Auxiliary Ventilation of Underground Coal Mining, Int. J. Coal Geology, 2009, vol. 80, no. 1, pp. 35-43.

11. Wiatowski, M., Stańczyk, K., Świądrowski, J., Kapusta, K., Cybulski, K., Krause, E., Grabowski, J., Rogut, J., Howaniec, N., and Smoliński, A., Semi-Technical Underground Coal Gasification (UCG) Using the Shaft Method in Experimental Mine Barbara, Fuel, 2012, vol. 99, pp. 170-179.

12. Luo, Y., Zhao, Y., Wang, Y., Chi, M., Tang, H., and Wang, S., Distributions of Airflow in Four Rectangular Section Roadways with Different Supporting Methods in Underground Coal Mines, Tunneling and Underground Space Technology, 2015, vol. 46, pp. 85-93.

13. Toraño, J., Torno, S., Menéndez, M., and Gent, M., Auxiliary Ventilation in Mining Roadways Driven with Roadheaders: Validated CFD Modelling of Dust Behavior, Tunneling and Underground Space Technology, 2011, vol. 26, no. 1, pp. 201-210.

14. Kurnia, J.C., Sasmito, A.P., Wong, W.Y., and Mujumdar, A.S., Prediction and Innovative Control Strategies for Oxygen and Hazardous Gases from Diesel Emission in Underground Mines, The Science of the Total Environment, 2014, vol. 481, pp. 317-334.

15. Haoran, Z., Pera, L.S., Zhao, Y., and Sanchez, C.V., Researches and Applications on Geostatistical Simulation and Laboratory Modeling of Mine Ventilation Network and Gas Drainage Zone, Process Safety and Environmental Protection, 2015, vol. 94, pp. 55-64.

16. Su, S., Chen, H., Teakle, P., and Xue, S., Characteristics of Coal Mine Ventilation air Flows, J. of Environmental Management, 2008, vol. 86, no. 1, pp. 44-62.

17. Karacan, C.Ö., Development and Application of Reservoir Models and Artificial Neural Networks for Optimizing Ventilation Air Requirements in Development Mining of Coal Seams, Int. J. of Coal Geology, 2007, vol. 72, no. 3-4, pp. 221-239.

18. Sasmito, A.P., Birgersson, E., Ly, H.C., and Mujumdar, A.S., Some Approaches to Improve Ventilation System in Underground Coal Mines Environment - a Computational Fluid Dynamic Study, Tunnelling and Underground Space Technology, 2013, vol. 34, pp. 82-95.

19. Nyaaba, W., Frimpong, S., and El-nagdy, K.A., Optimization of Mine Ventilation Networks Using the Lagrangian Algorithm for Equality Constraints, Int. J. Min., Reclamation and Environment, 2015, vol. 29, no. 3, pp. 201-212.

20. Xu, G., Jong, E.C., Luxbacher, K.D., Ragab, S.A., and Karmis, M.E., Remote Characterization of Ventilation Systems Using Tracer Gas and CFD in an Underground Mine, Safety Sci., 2015, vol. 74, pp. 140-149.

21. Alymenko, N.I., Aerodynamic Parameters of Ventilating Passages Joined-Up with the Main Mine Fan, J. Min. Sci., 2012, vol. 47, no. 6, pp. 814-823.

22. Song, X. and Mu, X., The Safety Regulation of Small-Scale Coal Mines in China: Analyzing the Interests and Influences of Stakeholders, Energy Policy, 2013, vol. 52, pp. 472-481. 